\title{
Assessment of Nurses' Perceptions and Adherence to Five Moments of Hand Hygiene in Selected Units at a University Teaching Hospital in Rwanda
}

\author{
Fulgence Maniriho $^{1 *}$, Lakshmi Rajeswaran $^{1,2}$, Anita Collins ${ }^{1,2}$, Geldine Chironda $a^{1,2}$ \\ ${ }^{1}$ School of Nursing and Midwifery, University of Rwanda, College of Medicine and Health Sciences, Kigali, Rwanda \\ ${ }^{2}$ Rory Meyers College of Nursing, New York. University, New York, USA
}

*Corresponding author: Fulgence Maniriho. School of Nursing and Midwifery, College of Medicine and Health Sciences, University of Rwanda, Remera Campus, 11 KG 47, Kigali, Rwanda. E-mail: maniful100@yahoo.fr

\begin{abstract}
Background

About 1.4 million people worldwide are affected by hand hygiene-associated infections from healthcare providers, and altered perceptions might be the contributory factor.

Objective

To assess nurses' perceptions and adherence to the "five moments of hand hygiene" in selected units at a University Teaching Hospital in Rwanda.

Methods

A descriptive cross-sectional design was used. A sample size of 84 nurses was selected using convenience sampling. The perceptions survey questionnaire and the observation checklist was used to collect data. Descriptive and inferential statistics were used to analyse the data.

Results

Sixty-nine (82.1\%) had a positive perception of susceptibility and severity, and $75(89.2 \%)$ had a positive perception of the benefits of hand hygiene. All $84(100 \%)$ and $67(79.8 \%)$ had a negative perception of perceived barriers and action (cues) to hand hygiene; respectively. Highest adherence rate $(82.1 \%)$ was after body fluid exposure risk, lowest before touching a patient $(27.4 \%)$, with an average adherence rate of 53.6\% to the "five moments." Qualification was associated with nurses' perceptions $(\mathrm{p}=.002)$ and department of work with adherence to hand hygiene $(\mathrm{p}=.001)$.
\end{abstract}

Conclusion

The overall perceptions of nurses were negative with inadequate adherence to hand hygiene practices. Therefore, this necessitates new strategies and reinforcement of hand hygiene among the nurses.

Rwanda J Med Health Sci 2019;2(2):160-171.

Keywords: Hand hygiene, perceptions, nurses, adherence, five moments

\section{Background}

Healthcare-associated infection (HCAI), also referred to as "nosocomial" or "hospital acquired infection" is an infection which is not present or incubating in the patient at the time of admission, but occurs during the process of care in a hospital or any other health care setting.[1] Though it is estimated that 1.4 million people globally are affected by preventable HCAI,[2] the prevalence ranges from $3.5 \%$ to $12 \%$ of hospitalised patients in developed countries and $5.7 \%$ to $19.1 \%$ in developing countries.[3] In 2011, the World Health Organization (WHO) reported that at any given time $7 \%$ of patients in high-income, and 10\% in low-income countries, will develop at least one HCAI.[4]

A review of nosocomial infections in some African countries such as Burkina Faso, Burundi, Cameroon,
Democratic Republic of Congo, Gabon, Ghana, Mali, Uganda, United Republic of Tanzania, and Senegal revealed a prevalence rate between 1.6\%-28.7\%.[3] In Rwanda, a study conducted in 2016 at University Teaching Hospital of Kigali (UTHK) revealed an overall HCAI prevalence rate of $15.1 \%$ with the highest rate in intensive care unit (ICU) $(50.0 \%)$, and the lowest rate in General surgery unit (12.1\%).[5] Other significant burdens related to HCAIs include antibiotic resistance in $50 \%$ or more of surgical site infections and severe economic cost to healthcare systems and society.[4,6]

Cross-contamination with contaminated health care providers (HCPs) hands is the most common transmission way of HCAIs in health facilities. [7] It is proven that about $50 \%$ of HCAIs occur due to HCPs hands. [8] As a solution to the HCAI burden, the WHO introduced an evidence-based concept of "My five 
moments for hand hygiene" in 2009 as a strategy to raise the hand hygiene compliance by HCPs and to reduce the HCAIs. [9] The five moments of hand hygiene for HCPs are: (1) before touching a patient; (2) before the clean/ aseptic procedure; (3) after body fluid exposure risk; (4) after touching a patient; and (5) after touching patient surroundings.[2]

Nurses are mostly in contact with patients among all HCPs,[10] and the main providers of physical care.[11] Hence their hands come into constant contact with patients, which increases the risk of cross-contamination of HCAIs.[9] Thus, nurses' hand hygiene compliance seems pivotal in preventing HCAIs and limiting the transmission of microorganisms.[10]

Though hand hygiene is a simple procedure, HCPs' hand hygiene compliance is as low as 40\%. [9] Furthermore, the WHO estimated in 2009 that the hand hygiene compliance rates are comprised between $5 \%$ and $81 \%$, with an average below 40\%.[7,12] The studies conducted in India and Brazil revealed that most of the HCPs do hand hygiene after patient care than before contact with the patient. $[2,9,13]$ Despite the low hand hygiene compliance rates, in various studies conducted in India, Iran and Arabia, the participants revealed good awareness and positive perceptions towards hand hygiene and HCAIs.[1,14-16] The most perceived barriers that hinder hand hygiene practice in different studies conducted in India, Iran and Uganda were busy workload, forgetfulness, lack of time for hand washing, location and shortage of sinks and water, gloves use, fearing skin problems, lack of hand hygiene products, lack of role model, encouragement and motivation. [14,16-18]

Although numerous health behaviour theories such as the Theory of Planned Behaviour, the Trans-theoretical Model and the Health Belief Model (HBM) have been used to inform health intervention designs, the HBM remains one of the most widely applied theories in the design and evaluation of health behaviour intervention. [19] The HBM was employed in this study as a guiding framework to explore nurses' perceptions and their adherence to preventive health behaviour (hand hygiene). The main concepts of the HBM comprise: (1) susceptibility to illness or risk of illness, (2) severity of illness or risk for severe illness or consequence from the illness,(3) barriers to action or difficulties to perform an action, (4) benefits of action, (5) cues to action or factors that prompt action and(6) self-efficacy or confidence in one's ability to perform an action.[20]

The reduction of HCAIs through hand hygiene was incorporated into the Rwanda Hospital Accreditation Standards.[21] Despite this, HCAIs are still prevalent $(15.1 \%)$ at the University Teaching Hospital of Kigali (UTHK).[5] However, the investigator did not find any study conducted on hand hygiene adherence among nurses at UTHK. Therefore, the current study aimed to assess the nurses' perceptions and adherence to the recommended WHO five moments of hand hygiene at UTHK. The specific objectives include: To characterise the nurses' perception of hand hygiene; To determine the level of adherence to WHO five moments of hand hygiene; To establish demographic factors associated with nurses' perceptions and adherence to five moments of hand hygiene.

\section{Methods}

\section{Design}

The study was a descriptive cross-sectional and observational study design to assess the nurses' perceptions and adherence to the WHO five moments of hand hygiene. The study was conducted in Rwanda specifically at the University Teaching Hospital of Kigali in intensive care and surgical departments from 30 March to 21 April 2017.

\section{Participants' recruitment}

The study population included 106 bedside nurses working in surgical (48) and intensive care (58) departments. The sample size of 84 bedside nurses was used, and it was calculated using the following formula:

$$
n=\frac{\frac{z^{2} p(1-p)}{e^{2}}}{\begin{array}{c}
1+\left(z^{2} p(1-p)\right. \\
e^{2} N
\end{array}}
$$

$\mathrm{n}=$ Sample size: $\mathrm{e}=5 \%$ Margin of error: $\mathrm{N}=$ Population: $Z=1.96$ z-score: $P=50 \%$ Sample proportion

\section{Sampling strategy}

The units; General Surgery, Orthopedic/Burn, Neurosurgery, ICU/adults, ICU/pediatrics and Neonatal Intensive Care Ward were the strata. The same sampling fraction $(84 / 106)$ was used to calculate the number of nurses to be selected in each stratum. Based on the number of bedside nurses in each stratum, the calculated sample of nurses in each stratum was as follows: General surgery (14), Orthopedic/Burn (14), Neurosurgery (10), ICU/adults (23), ICU/pediatrics (12) and Neonatal Intensive Care Ward (11). Thus, the convenient sampling was used to select the predetermined sample in each stratum.

\section{Instrument}

The nurses' perceptions on hand hygiene and HCAIs was assessed using the perception questionnaire that was developed based on the tenets of the Health Belief Model and the WHO "Perception Survey for HealthCare Workers" questionnaire developed in 2009. It was a self-administered questionnaire made of two main sections, namely socio-demographic characteristics of the respondents and questions on perception, constructed on a five-point Likert scale and grouped into four categories:(1) perceived susceptibility/ severity 
of HCAIs, (2) perceived benefits of hand hygiene, (3) perceived barriers to hand hygiene, and (4) cues to take hand hygiene action. The questionnaire was in the English language, and it took about 10 to 15 minutes to fill out. The WHO hand hygiene observation form revised in 2009 was adapted to observe hand hygiene adherence to the WHO five moments. The observation form consisted of the WHO five moments for hand hygiene and the corresponding options to tick hand hygiene action as "missed, hand rub, hand washing". The reliability for the developed questionnaire was measured by SPSS software version 21 for a sample of 30 participants used in the pilot study, and the Cronbach's Alpha was 0.73 , which was considered reliable. To ensure the content validity, the research experts at the University checked, analysed and validated the questions inside the developed tool.

\section{Data collection}

Two methods of data collection were used. Firstly, the self-administered questionnaire was used to gather information about nurses' perceptions of hand hygiene and HCAIs. Secondly, direct observation was carried out to collect data about nurses' adherence to the WHO five moments of hand hygiene. Direct observation is considered the gold standard for hand hygiene monitoring. [7] A pretesting was conducted to assess the feasibility of the study. After obtaining permission from the University and UTHK authorities, the questionnaire was pre-tested among 30 bedside nurses from the UTHK, but who were not part of the main study. This helped to rectify the ambiguity of the questionnaire. The three questions (one question under the perceived susceptibility and severity, and two questions under the perceived benefits of hand hygiene) were confusing, and they were reframed to increase clarity.

Regarding the direct observation, the inter-rater reliability was achieved by involving the research assistant (unemployed nurse with Bachelor's degree in General Nursing) who was trained and assessed by the investigator for the understanding of the WHO concept of five moments for hand hygiene and completion of the WHO observation form during data collection. After that, concordance in hand hygiene observations between the trained observer and the investigator was established in two departments (Surgical and ICU) before the actual observation sessions are conducted. The trained observer and the investigator observed hand hygiene opportunities and actions during a patient care situation each completed the observation form separately while observing the same HCP and the same care sequence in the same unit and at the same time. Then the measured rates of compliance were compared, and discordant notifications were discussed. To achieve concordance between two observers in terms of the number and nature of each hand hygiene opportunity that occurred; this process was carried out two times in the surgical department and three times in ICU. The same approach was described and used by the investigators in their studies.[22,23]
Data collection occurred on weekdays between 8:a.m and 7:00 p.m.during four weeks from $30^{\text {th }}$ March to $21^{\text {st }}$ April 2017. Arrangements had already been made with the unit managers, and participants were approached individually and invited to be involved in the study. The study was explained, consents were signed, and participants were given adequate time to complete the questionnaire. The nurses who were questioned were the same ones observed in this study. To enhance the identification, a code number was used on both data collection tools.

The observers became passive observers, observing hand hygiene activity using the observation checklist. To reduce the Hawthorne effect, which is when individuals are aware that they are being observed and change their behaviour to meet the observer's expectations; [24] the following strategies were employed. (1) The observation sessions were conducted in the same period of questionnaires distribution; the period in which the participants could think that the physical presence of the investigators in wards was for questionnaires distribution only yet two activities were being concomitantly conducted. Each observation session was initiated at the time the nurses were busy caring for patients, and the observers were dressed in nurses' uniform. (2) The observers were standing at a certain distance that allowed them to see what was happening without interfering with patient care activities. (3) The observers kept changing the location (after five observations), moving about from one unit to another at the end of each observation session on a unit.

The observers watched while counting and recording the hand hygiene opportunities that were occurring during the care activity sequence, and the hand hygiene actions performed by the nurse. The time the observer identified an indication for hand hygiene, it was counted, as an opportunity to which there would be a corresponding positive or negative action. Only the frequency of hand hygiene and not the quality was evaluated. The use of gloves was only recorded when the HCP under observation used gloves at the time an opportunity occurred and did not perform a hand hygiene action. The observation sessions were conducted until the predetermined sample size in each unit was reached.

\section{Data analysis}

Data were analysed using the Statistical Package for Social Sciences (SPSS software version 21), and the Microsoft Excel was used to produce figures on hand hygiene adherence. Descriptive statistics were used to describe the nurses' perceptions and adherence to five moments of hand hygiene. The chi-square test was used to measure the association between socio-demographic characteristics with nurses' perceptions and adherence to hand hygiene. Adherence rate was calculated using the following formula as recommended by WHO, [7] and the study by Taneja and Mishra.[13]

Total number of acts of hand hygiene when the opportunity existed $\mathrm{x} 100$ Total number of hand hygiene opportunities 


\section{Ethical considerations}

The ethical clearance was obtained from the University of Rwanda, College of Medicine and Health Sciences, Institutional Review Board (IRB) and from the UTHK research committee. Participation in the study was voluntary, and the participants approved their participation by signing the informed consent. Both questionnaires and observation forms used for data collection were anonymous bearing only codes.

\section{Results}

Socio-demographic characteristics of study participants The majority was female $70(83.3 \%)$ and aged between 3545 years old (table 1). Most of the participants $74(88.1 \%)$ held an advanced diploma certificate (A1), and 34(40.5\%) had 5-10 years of work experience. Over a quarter of 23 $(27.4 \%)$ were from adult ICU and fewer 10 (11.9\%) from Neurosurgery. The majority $60(71.4 \%)$ had in-service hand hygiene training in the last three years.

Table 1. Socio-demographic Characteristics of Participants $(\mathrm{n}=84)$

\begin{tabular}{ll}
\hline Variable & $\mathbf{n}(\mathbf{\%})$ \\
\hline Gender & \\
Female & $70(83.3)$ \\
Male & $14(16.7)$ \\
Age (years) & \\
$<25$ & $3(3.6)$ \\
$25-35$ & $33(39.3)$ \\
$36-45$ & $38(45.2)$ \\
$46-55$ & $10(11.9)$ \\
Participants' qualification & \\
Bachelor's degree (A0) & $5(6.0)$ \\
Advanced diploma (A1) & $74(88.1)$ \\
Secondary school diploma (A2) & $5(6.0)$ \\
Department of work & \\
General Surgery & $14(16.7)$ \\
Orthopedic/Burn & $14(16.7)$ \\
Neurosurgery & $10(11.9)$ \\
ICU/Adults & $23(27.4)$ \\
ICU/Pediatrics & $12(14.3)$ \\
Neonatal Intensive Care Unit & $11(13.1)$ \\
Work experience (years) & \\
$<5$ & $28(33.3)$ \\
5-10 & $34(40.5)$ \\
11-15 & $14(16.7)$ \\
In-service training on hand hygiene & $8(9.5)$ \\
Yes & $60(71.4)$ \\
No & $24(28.6)$ \\
\hline
\end{tabular}

Perception of susceptibility and severity of HCAIs As shown in table 2, the 5-point Likert Scale was used to gather participants' perception on nine items about susceptibility and severity of HCAI. The majority $88(98.8 \%)$ including $33(39.3 \%)$ and $50(59.5 \%)$, respectively agreed and strongly agreed that contaminated HCPs hands cause the greatest risk of transmitting HCAI to patients, patient relatives and self contamination, $97.6 \%$ including $23(27.4 \%)$ and $59(70.2 \%)$, respectively agreed and strongly agreed that nurses are more vulnerable than other HCPs to contamination with HCAI, 96.4\% including 23 (27.4\%) and 58 (69.0\%), respectively agreed and strongly agreed that HCPs, patients and relatives are at risk of acquiring HCAI and $95.2 \%$ including $28(33.3 \%)$ and $52(61.9 \%)$, respectively agreed and strongly agreed that HCAI is associated with prolonged hospitalization. About 55(65.5\%) and 18(21.4\%), respectively agreed and strongly agreed with the high impact of HCAIs on patient's clinical outcome. 
Table 2. Perception of Susceptibility and Severity of HCAIs $(n=84)$

\begin{tabular}{llllll}
\hline $\begin{array}{l}\text { Perceived susceptibility and } \\
\text { perceived severity of HCAI }\end{array}$ & $\begin{array}{l}\text { Strongly } \\
\text { Disagree }\end{array}$ & Disagree & $\begin{array}{l}\text { Undecided } \\
\text { n (\%) }\end{array}$ & Agree & $\begin{array}{l}\text { Strongly } \\
\text { Agree }\end{array}$ \\
\hline $\begin{array}{l}\text { HCPs, patients and patient relatives are } \\
\text { at risk of acquiring HCAIs }\end{array}$ & $0(0.0)$ & $0(0.0)$ & $3(3.6)$ & $23(27.4)$ & $58(69.0)$ \\
$\begin{array}{l}\text { Nurses are more vulnerable than other } \\
\text { HCPs to contamination with HCAIs }\end{array}$ & $0(0.0)$ & $2(2.4)$ & $0(0.0)$ & $23(27.4)$ & $59(70.2)$ \\
$\begin{array}{l}\text { Contaminated HCPs hands cause the } \\
\text { greatest risk of transmitting HCAIs to } \\
\text { patients, relatives and oneself }\end{array}$ & $0(0.0)$ & $0(0.0)$ & $1(1.2)$ & $33(39.3)$ & $50(59.5)$ \\
$\begin{array}{l}\text { HCAI is globally a major problem in } \\
\text { hospitals }\end{array}$ & $0(0.0)$ & $4(4.8)$ & $8(9.5)$ & $39(46.4)$ & $33(39.3)$ \\
$\begin{array}{l}\text { HCAI a major cause of preventable } \\
\text { deaths and disability worldwide }\end{array}$ & $2(2.3)$ & $5(6.0)$ & $12(14.3)$ & $46(54.8)$ & $19(22.6)$ \\
$\begin{array}{l}\text { HCAI is associated with a prolonged } \\
\text { patient hospital stay }\end{array}$ & $1(1.2)$ & $3(3.6)$ & $0(0.0)$ & $28(33.3)$ & $52(61.9)$ \\
$\begin{array}{l}\text { HCAI causes high costs for the health } \\
\text { systems }\end{array}$ & $0(0.0)$ & $2(2.4)$ & $7(8.3)$ & $43(51.2)$ & $32(38.1)$ \\
$\begin{array}{l}\text { HCAI causes emotional stress for } \\
\text { patients and their families }\end{array}$ & $1(1.2)$ & $1(1.2)$ & $6(7.1)$ & $53(63.1)$ & $23(27.4)$ \\
$\begin{array}{l}\text { Impact of HCAI on a patient's clinical } \\
\text { outcome is high }\end{array}$ & $1(1.2)$ & $5(6.0)$ & $5(6.0)$ & $55(65.5)$ & $18(21.5)$ \\
\hline
\end{tabular}

Perception of the benefits of hand hygiene

As presented in table 3, the 5-point Likert Scale was used to gather participants' perception on ten items about the benefits of hand hygiene. All participants 84(100 $\%$ ) agreed that hand hygiene is the primary major for preventing and reducing HCAIs. Almost all participants $81(96.4 \%)$ agreed on the importance of hand hygiene at the WHO five moments of hand hygiene. About $78(92.9 \%)$ including $33(39.3 \%)$ and 45 (53.6\%), respectively agreed and strongly agreed that hand hygiene is an economical method for reducing HCAIs. The same percentage was in agreement that the effectiveness of hand hygiene in preventing HCAI is high.

Table 3. Perception of Benefits of Hand Hygiene $(n=84)$

\begin{tabular}{|c|c|c|c|c|c|}
\hline Perceived Benefits of Hand Hygiene & $\begin{array}{l}\text { Strongly } \\
\text { Disagree }\end{array}$ & Disagree & $\begin{array}{l}\text { Undecided } \\
\mathrm{n}(\%)\end{array}$ & Agree & $\begin{array}{l}\text { Strongly } \\
\text { Agree }\end{array}$ \\
\hline $\begin{array}{l}\text { Hand hygiene is the primary for } \\
\text { preventing and reducing HCAIs }\end{array}$ & $0(0.0)$ & $0(0.0)$ & $0(0.0)$ & $27(32.1)$ & $57(67.9)$ \\
\hline $\begin{array}{l}\text { Hand hygiene is an economical method } \\
\text { for reducing HCAIs }\end{array}$ & $1(1.2)$ & $3(3.6)$ & $2(2.4)$ & $33(39.3)$ & $45(53.6)$ \\
\hline $\begin{array}{l}\text { Hand hygiene practices help control } \\
\text { epidemics in health-care facilities }\end{array}$ & $1(1.2)$ & $3(3.6)$ & $3(3.6)$ & $47(56.1)$ & $30(35.7)$ \\
\hline Hand hygiene is cost-saving & $1(1.2)$ & $6(7.1)$ & $25(29.8)$ & $27(32.1)$ & $25(29.8)$ \\
\hline $\begin{array}{l}\text { Hand hygiene practice before touching a } \\
\text { patient interrupts microbial transmission } \\
\text { to the patient }\end{array}$ & $0(0.0)$ & $0(0.0)$ & $0(0.0)$ & $13(15.5)$ & $71(84.5)$ \\
\hline $\begin{array}{l}\text { Hand hygiene practice before a clean/ } \\
\text { aseptic procedure interrupts microbial } \\
\text { transmission to the patient }\end{array}$ & $0(0.0)$ & $0(0.0)$ & $0(0.0)$ & $16(19.0)$ & $68(81.0)$ \\
\hline
\end{tabular}


Hand hygiene practice after touching a patient interrupts microbial transmission to HCP
$0(0.0)$
$0(0.0)$
$0(0.0)$
$18(21.4) \quad 66(78.6)$

Hand hygiene practice after body fluid exposure risk interrupts microbial $0(0.0)$

$0(0.0)$

$2(2.4)$

$16(19.2) \quad 66(78.6)$

transmission to HCP

Hand hygiene practice after touching

patient surroundings interrupts microbial
$0(0.0)$
$0(0.0)$
$1(1.2)$
$23(27.4)$
$60(71.4)$

transmission to the HCP

Generally, the effectiveness of hand

hygiene in preventing HCAI is high
$0(0.0)$
$1(1.2)$
$5(6.0)$
$43(51.2) \quad 35(41.7)$

\section{Cues to action (Hand hygiene action)}

As presented in table 4, the 5-Likert Scale was used to gather participants' perception of twelve items about the cues to hand hygiene action. The findings revealed that most of the perceived cues to take hand hygiene action included leaders and senior managers who support and openly promote hand hygiene $(97.7 \%)$, hand hygiene posters at point of care (94\%), visible, clear and straightforward instructions for hand hygiene $(92.9 \%)$, in-service education $(78.6 \%)$, alcohol-based hand rub (77.4\%), safe continuous water supply, soap and towels $(61.9 \%)$. However, a total of $59(70.2 \%)$ participants were in disagreement with inviting patients to remind HCPs to perform hand hygiene.

Table 4. Cues to Action (Hand hygiene action) $(n=84)$

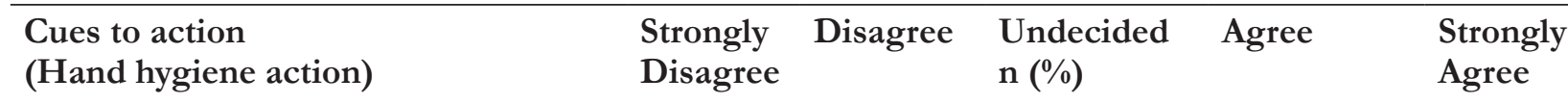

Leaders and senior managers at your institution support and openly promote hand hygiene

The health care facility makes alcoholbased hand rub always available at each point of care

Hand hygiene posters are displayed at the point of care

Each HCP receives in-service education on hand hygiene

Clear and simple instructions for hand hygiene are made visible for every HCP

HCPs regularly receive feedback on their hand hygiene performance

Serving as a role model for your colleagues by performing hand hygiene as recommended by WHO

Patients at your institution are invited to remind HCPs to perform hand hygiene Hand hygiene campaigns are conducted at your institution

$0(0.0)-1(1.2)$

$1(1.2)$

$46(54.7)$

$36(42.9)$

$0(0.0) \quad 8(9.5) \quad 11(13.1) \quad 43(51.2) \quad 22(26.2)$

$\begin{array}{llll}0(0.0) & 0(0.0) \quad 5(6.0) & 49(58.3) & 30(35.7)\end{array}$

$1(1.2) \quad 5(6.0) \quad 12(14.3) \quad 46(54.7) \quad 20(23.8)$

$0(0.0) \quad 0(0.0) \quad 6(7.1) \quad 52(61.9) \quad 26(31.0)$

$8(9.6) \quad 28(33.3) \quad 19(22) \quad .17(20.2) \quad 12(14.3)$

$2(2.4) \quad 16(19.0) \quad 28(33.3) \quad 23(27.4) \quad 15(17.9)$

$29(34.5) \quad 30(35.7) \quad 8(9.5) \quad 11(13.1) \quad 6(7.2)$

$11(13.1) \quad 33(39.3) \quad 16(19.0) \quad 15(17.9) \quad 9(10.7)$

Safe continuous water supply, soap and towels are always available at your institution

Peers always advise hand hygiene

Organisation conducts mass media

advertisement of hand hygiene

$\begin{array}{lllll}1(1.2) & 16(19.0) & 15(17.9) & 34(40.5) & 18(21.4) \\ 1(1.2) & 31(36.8) & 12(14.3) & 25(29.8) & 15(17.9) \\ 15(17.9) & 33(39.3) & 22(26.2) & 8(9.5) & 6(7.1)\end{array}$




\section{Perception of barriers for hand hygiene}

The most perceived barriers for hand hygiene were lack of material $(41.7 \%)$ such as soap, paper towel, alcoholbased hand rub, water; being too busy $(29.8 \%)$, use of gloves $(28.6 \%)$ and forgetfulness $(25 \%)$. The majority of participants were in disagreement with regard to various barriers for hand hygiene such as lack of rewards/ encouragement $(94.1 \%)$, lack of institutional priority for hand hygiene $(94 \%)$, perceiving hand hygiene as not convenient (89.3\%), allergic reactions with hand hygiene $(88.1 \%)$, unsure of need to hand washing $(85.7 \%)$ and interference of hand hygiene with HCP-Patient relationship (81\%).

Table 5. Perception of Barriers for Hand Hygiene $(n=84)$

\begin{tabular}{|c|c|c|c|c|c|}
\hline $\begin{array}{l}\text { Perceived barriers for hand } \\
\text { hygiene }\end{array}$ & $\begin{array}{l}\text { Strongly } \\
\text { Disagree }\end{array}$ & Disagree & Undecided & Agree & $\begin{array}{l}\text { Strongly } \\
\text { Agree }\end{array}$ \\
\hline $\begin{array}{l}\text { Perceiving hand hygiene as not } \\
\text { convenient }\end{array}$ & $33(39.3)$ & $42(50.0 \%)$ & $2(2.4)$ & $5(6.0)$ & $2(2.4)$ \\
\hline $\begin{array}{l}\text { Lack of material (soap, paper towel, } \\
\text { alcohol-based hand rub, water) }\end{array}$ & $17(20.2)$ & $22(26.2)$ & $10(11.9)$ & $32(38.1)$ & $3(3.6)$ \\
\hline $\begin{array}{l}\text { Allergic reactions with a hand } \\
\text { hygiene product }\end{array}$ & $33(39.3)$ & $41(48.7)$ & $5(6.0)$ & $3(3.6)$ & $2(2.4)$ \\
\hline Being too busy & $18(21.4)$ & $25(29.8)$ & $16(19.0)$ & $23(27.4)$ & $2(2.4)$ \\
\hline Forgetfulness & $14(16.7)$ & $36(42.9)$ & $13(15.5)$ & $18(21.4)$ & $3(3.6)$ \\
\hline Unsure of the need to hand wash & $28(33.3)$ & $44(52.4)$ & $5(6.0)$ & $4(4.8)$ & $3(3.6)$ \\
\hline Inadequate hand washing facility & $19(22.6)$ & $43(51.2)$ & $10(11.9)$ & $11(13.1)$ & $1(1.2)$ \\
\hline $\begin{array}{l}\text { A belief that when using gloves, no } \\
\text { need for hand hygiene }\end{array}$ & $22(26.2)$ & $22(26.2)$ & $16(19.0)$ & $23(27.4)$ & $1(1.2)$ \\
\hline $\begin{array}{l}\text { Hand hygiene interferes with HCP- } \\
\text { patient relationship }\end{array}$ & $26(31.0)$ & $42(50.0)$ & $10(11.9)$ & $5(6.0)$ & $1(1.2)$ \\
\hline $\begin{array}{l}\text { Lack of institutional priority for } \\
\text { hand hygiene }\end{array}$ & $29(34.5)$ & $50(59.5)$ & $2(2.4)$ & $2(2.4)$ & $1(1.2)$ \\
\hline $\begin{array}{l}\text { Lack of rewards and, or } \\
\text { encouragement }\end{array}$ & $34(40.5)$ & $45(53.5)$ & $1(1.2)$ & $3(3.6)$ & $1(1.2)$ \\
\hline
\end{tabular}

\section{Nurses' perception scores}

The overall perception of study participants on susceptibility and severity of HCAI, benefits of hand hygiene, hand hygiene actions and barriers to hand hygiene was computed, and the score was calculated. The responses ranged from $1=$ strongly disagree, $2=$ disagree, $3=$ undecided, 4=agree and 5=strongly agree. The response "agree" or "strongly agree" on each item was considered as a positive response.

Regarding the susceptibility and severity of HCAI, there were nine items, the minimum score was nine, and the maximum score was 45 . Thus, the score of $36 / 45$ (80\%) was taken as the cutoff point. Any score equal or above 36 was categorised as positive perception while the score lower than 36 was categorised as negative perception. The computed results indicated that the majority of participants $69(82.1 \%)$ had a positive perception of susceptibility and severity of HCAI.

Benefits of hand hygiene had ten items, the minimum score was 10 , and the maximum score was 50 . Thus, the score of $40 / 50(80 \%)$ was taken as the cutoff point. Any score equal or above 40 was categorised as positive perception, while the score lower than 40 was categorised as negative perception. The computed results indicated that the majority of participants $75(89.2 \%)$ had a positive perception of the benefits of hand hygiene.

There were 12 items for the hand hygiene action, the minimum score was 12, and the maximum score was 60 . Thus, the score of $48 / 60(80 \%)$ was taken as the cutoff point. Any score equal or above 48 was categorised as positive perception while the score lower than 48 was categorised as negative perception. The computed results indicated that the majority of participants 67 $(79.8 \%)$ had a negative perception of cues to hand hygiene action. Only $17(20.2 \%)$ participants had a positive perception of cues to hand hygiene action.

There were 11 items for the barriers to hand hygiene action with a minimum score of 11 and the maximum score of 55 . Thus, the score of 44/55 (80\%) was taken as the cutoff point and was categorised as positive 
perception while the score lower than 44 was categorised as negative perception. The computed results indicated that all $84(100 \%)$ participants had a negative perception of barriers to hand hygiene action. None of the participants had a positive perception of barriers to hand hygiene action.

Table 6. Nurses Perception Scores $(n=84)$

\begin{tabular}{lll}
\hline Nurses' perception scores & n (\%) & Perception \\
\hline $\begin{array}{l}\text { Perception score of susceptibility } \\
\text { and severity of HCAI out of } \mathbf{4 5}\end{array}$ & $15(18.0)$ & $\begin{array}{l}\text { Negative } \\
\text { Positive }\end{array}$ \\
$\begin{array}{l}\text { Score } 21 \text { to } 35 \\
\text { Pere } 36 \text { to } 45\end{array}$ & $69(82.0)$ & \\
$\begin{array}{l}\text { Perception score of benefits of } \\
\text { hand hygiene out of 50 }\end{array}$ & $9(11.0)$ & Negative \\
$\begin{array}{l}\text { Score } 37 \text { to } 39 \\
\text { Score } 40 \text { to } 50\end{array}$ & $75(89.0)$ & Positive \\
$\begin{array}{l}\text { Perception score for cues to action/ } \\
\text { hand hygiene action out of } \mathbf{6 0}\end{array}$ & & \\
$\begin{array}{l}\text { Score } 30 \text { to } 47 \\
\text { Score } 48 \text { to } 60\end{array}$ & $17(20.0)$ & $\begin{array}{l}\text { Negative } \\
\text { Scores on perception of barriers } \\
\text { for hand hygiene out of 55 }\end{array}$ \\
$\begin{array}{l}\text { Score } 11 \text { to } 43 \\
\text { Score } 44 \text { to } 55\end{array}$ & $84(100)$ & $\begin{array}{l}\text { Negative } \\
\text { Overall nurses' perception on hand } \\
\text { hygiene out of } 210\end{array}$ \\
$\begin{array}{l}\text { Score } 122 \text { to } 166 \\
\text { Score } 166 \text { to } 210\end{array}$ & $0(0)$ & Positive \\
\hline
\end{tabular}

The adherence rates to specific WHO five moments of hand hygiene

As shown in figure 1, the high adherence rate $(82.1 \%)$ occurred after body fluid exposure risk, $61.9 \%$ and $60.7 \%$ of adherence rates occurred before clean/aseptic technique, and after touching a patient, respectively. The low adherence rates $(27.4 \%$ and $35.7 \%)$ occurred before touching a patient and after touching patient surroundings, respectively.

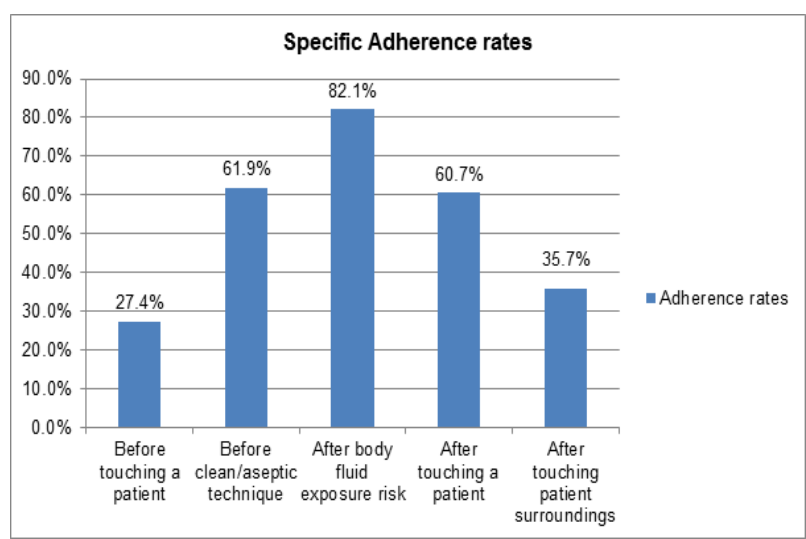

Figure 1. Adherence rates to each WHO five moment of hand hygiene
The overall adherence rate to the WHO five moments of hand hygiene

Using the observation checklist, a total of 420 hand hygiene opportunities occurred, and 225 hand hygiene actions were observed and recorded on the observation checklist. The average adherence rate to WHO five moments of hand hygiene was $53.6 \%$ as calculated taking the observed hand hygiene actions, multiplied by one hundred, and divided by the total hand hygiene opportunities that occurred.

Adherence rate to the WHO five moments of hand hygiene by qualification

As presented in figure 2, the advanced diploma holder nurses (A1) were the majority $(n=74)$ and had an adherence rate of $54.0 \%$, while the Secondary school diploma (A2) and Bachelor's degree (A0) holder nurses, were in the minority ( $\mathrm{n}=5$ for each) and had adherence rates of $52.0 \%$ and $48.0 \%$, respectively. 


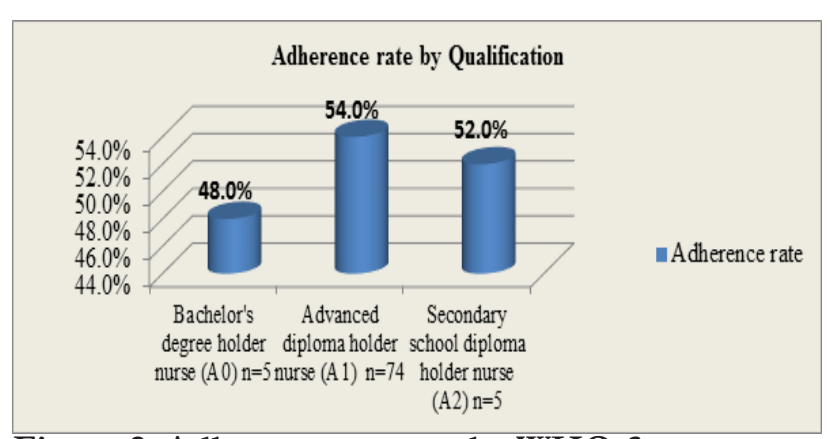

Figure 2. Adherence rate to the WHO five moments of hand hygiene by qualification

Adherence rate to the WHO five moments of hand hygiene by the department of work

As presented in figure 3 , the high adherence rate $(90.9 \%)$ of the WHO five moments of hand hygiene was observed in Neonatal Intensive Care Unit (NICU), followed by ICU/Adults (56.5\%). The low adherence rates of $48.6 \%, 43.3 \%$ and $34.3 \%$ were observed in General Surgery, ICU/Pediatrics and Orthopedic/Burn, respectively.

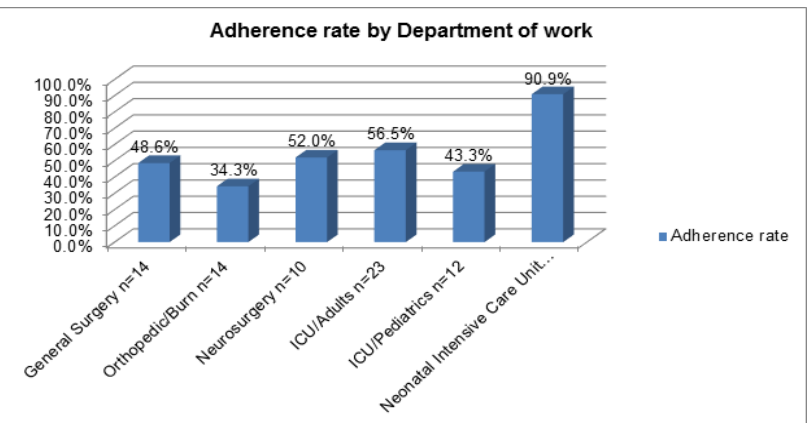

Figure 3. Adherence rate to WHO five moments of hand hygiene by work department

Adherence rate to the WHO five moments of hand hygiene by in-service training in hand hygiene

As indicated in figure 4, the majority of participants $(\mathrm{n}=60)$ who received in-service training in hand hygiene had an adherence rate of $54.6 \%$, while the minority $(\mathrm{n}=24)$ who did not receive in-service training in hand hygiene had an adherence rate of $50.8 \%$.

\section{Adherence rate by in service training in hand hygiene}

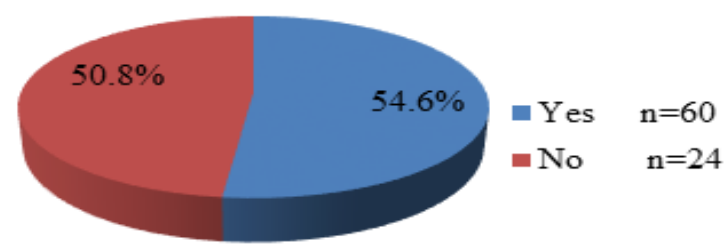

Figure 4. Adherence rate to the WHO five moments of hand hygiene by in-service training in hand hygiene
Association between socio-demographic characteristics with nurses' perceptions and hand hygiene adherence The Chi-square was used to test the association between socio-demographic characteristics with nurses' perceptions and adherence to hand hygiene. The total scores for nurses' perceptions and adherence to hand hygiene were computed and cross-tabulated with socio-demographic characteristics. As shown in table 7 , there was only an association between the qualification of the participants with nurses' perceptions $(p=.002)$ and an association between the department of work with adherence to hand hygiene $(\mathrm{p}=.001)$.

Table 7: Association Between Socio-demographic Characteristics with Nurses' Perceptions and Hand Hygiene Adherence $(n=84)$

\begin{tabular}{|c|c|c|}
\hline $\begin{array}{l}\text { Demographic } \\
\text { variable }\end{array}$ & $\begin{array}{l}\text { Nurses } \\
\text { perception }\end{array}$ & $\begin{array}{l}\text { Adherence to } \\
\text { five moments } \\
\text { of hand } \\
\text { hygiene } \\
\text { p value }\end{array}$ \\
\hline Gender & .135 & .854 \\
\hline Age & .090 & .639 \\
\hline Qualification & .002 & .987 \\
\hline Department of work & .303 & .001 \\
\hline Years of experience & .415 & .578 \\
\hline In-service training & .719 & .115 \\
\hline
\end{tabular}

\section{Discussion}

This study aimed to assess the nurses' perceptions and adherence to the recommended WHO five moments of hand hygiene at UTHK. The findings were discussed systematically as per the study objectives.

\section{Perception of susceptibility and severity of HCAI} Participants $(82.1 \%)$ revealed a positive perception of susceptibility and severity of HCAI. Specifically, more participants agreed (65.5\%) and strongly agreed $(21.4 \%)$ that the impact of HCAI on a patient's clinical outcome is high. These findings are quite similar to those from a study conducted in Saudi Arabia where most of the participants believed that there is a high (54\%) and very high $(21.5 \%)$ impact of HCAIs on patient clinical outcome.[1] Individuals with a positive perception of susceptibility (risk assessment and vulnerability) and severity (of HCAI) would likely adhere to hand hygiene, a proven primary preventive behaviour to reduce HCAIs.[16] However, it is not always the case as some individuals may possess good knowledge and perceive well about a particular disease but still fail to take preventive health behaviour. A study revealed that having good knowledge of hand hygiene, social influence or moral perceptions do not necessarily result in good hand hygiene practice,[25] instead self-efficacy is a determinant factor for hand hygiene compliance.[1] 


\section{Perception of the benefits of hand hygiene}

The majority of participants $(89.2 \%)$ had a positive perception of the benefits of hand hygiene, and all $(100 \%)$ perceived that hand hygiene was the primary measure for preventing and reducing HCAIs. Similarly, a study conducted in Saudi Arabia found that nearly all $(99 \%)$ agreed that hand hygiene is the single and most effective technique against HCAIs.[1] A positive perception implies a good understanding that the benefits of hand hygiene outweigh the barriers.

\section{Cues to action (Hand hygiene action)}

Though most participants (97.7\%) agreed that leadership supported and promoted hand hygiene, a relatively large number of participants $(79.8 \%)$ generally had a negative perception of cues to hand hygiene action. This implicated that a lot still needs to be done at the institutional, managerial level for better implementation of the WHO Multimodal Hand Hygiene Improvement Strategy. Many participants $(70.2 \%)$ disagreed that patients should remind HCPs to perform hand hygiene, similar to a study in Saudi Arabia whereby only a limited number $(26.4 \%)$ perceived this as a cue to hand hygiene action.[1] A 2013 literature review revealed that this patient action increased hand hygiene compliance by $50 \% \cdot[17]$

\section{Perception of barriers for hand hygiene}

The perceived barriers to hand hygiene were lack of materials (41.5\%), such as soap, paper towel, alcoholbased hand rub, water; too busy (29.8\%), using gloves $(28.6 \%)$ and forgetfulness $(25 \%)$. The same barriers were cited in studies from India,[14] Uganda,[18] and a literature review.[17] Also, 20 situations were observed where hand hygiene was missed and instead participants used gloves. All these findings indicate that barriers still hinder hand hygiene adherence; even though the HBM Theory articulates that the perceived benefits should override the perceived barriers for adopting a preventive health behaviour.[19]

\section{Adherence to the WHO Five moments of hand hygiene}

An overall adherence rate of $53.6 \%$ demonstrated that nearly half $(46.4 \%)$ of participants were not practising the WHO five moments of hand hygiene. The observed low adherence rate was in the range of compliance rates estimated by WHO (5\%-81\%, with an average below $40 \%) .[7,12]$ The low hand hygiene adherence rate $(43.7 \%)$ was observed in a study conducted in Brazil,[2] and in India; and an intervention increased the baseline hand hygiene adherence rate of $52 \%$ to $63 \%$.[13] Based on these findings, it is evident that the WHO five moments for hand hygiene are not adequately practised and likely worldwide problem among HCPs.[12] According to the WHO, low compliance rate equates to missed actions.[7]

The highest hand hygiene adherence rate was observed after body fluid exposure risk (82.1\%), and the lowest was observed before touching a patient $(27.4 \%)$, similar to a study in India.[13] These findings are also similar to a study conducted in Brazil which revealed that the moment (indication) "before touching a patient" was most likely to be missed,[18] and the lowest adherence rates to hand hygiene were before touching the patient $(18.4 \%)$ and before aseptic procedure (20.9\%).[2] Given these findings, it appears that many HCPs prefer to perform hand hygiene after patient contact rather than before, which indicated they perceived their risk of susceptibility and severity of illness more important than the patient.

\section{Hand hygiene adherence by socio-demographic characteristics}

The advanced diploma holder nurses had an adherence rate of $54.0 \%$, while the adherence rate for Bachelor's degree holder and Secondary school diploma nurses, was $52.0 \%$ and $48.0 \%$, respectively. A similar finding was reported in the study by Ryan,[26] where there was no difference in hand hygiene adherence among nurses with a College Diploma, compared to those with University Degree. In addition, this study found an association $(p=.002)$ between the qualification level of participants with their perceptions, but there was no association ( $p$-value $=.987)$ of qualification level with hand hygiene adherence. This implicates that the educational level may raise an individual awareness/perception, but the individual still fails to adopt a health behaviour action. This was supported by Ryan,[26] that formal hand hygiene education did not affect the hand hygiene practices of HCPs.

There was no major difference identified among nurses who attended the in-service training on hand hygiene against those who did not attend it. In addition, there was no statistical association $(p=.115)$ between inservice training in hand hygiene, with hand hygiene adherence. The 2013 literature review supported these findings and highlighted that hand hygiene adherence goes beyond education and training as it involves continuous motivation towards change and sustaining that change.[17] Instead, self-efficacy was considered as a determinant factor for hand hygiene compliance rather than possessing only good theoretical knowledge on hand hygiene or social influence or moral perceptions on hand hygiene.[1]

The NICU adherence to hand hygiene technique was higher $(90.9 \%)$ than the general wards. There was also a statistical association $(\mathrm{p}=.001)$ between the department of work with hand hygiene adherence. Hand hygiene is quality care and safety issue for the hospitalised patient, but critical for the neonates as approximately 1 million die on the first day and another one million within the next six days.[27] However, it was disappointing to witness low hand hygiene adherence rates in some 
general wards, yet they were reported to have higher HCAI prevalence. [3,5]

\section{Limitations}

The current research has limitations. The study was conducted at one teaching hospital so the results cannot be generalised to other hospitals in Rwanda. The sample size was small, and there were only selected hospital departments, so using a larger sample and different departments may reveal different findings. Data were collected on weekdays, so compliance with hand hygiene rates would likely be different on nights and weekends. Despite various strategies used to reduce the Hawthorne effect, its perfect reduction was not achieved since it was not possible for the observers to conduct the observation sessions while completely hidden.

\section{Future research}

A qualitative component or intervention could be added to the current survey to explore the factors associated with poor hand hygiene adherence and the effective strategies to raise the adherence to hand hygiene. The study can be expanded to different referral and district hospitals to enhance the generalisation of the study findings.

\section{Conclusion}

Registered nurses working in the UTHK demonstrated positive perceptions about HCAI and hand hygiene benefits, but inadequate practice adherence to the WHO five moments of hand hygiene. The observed low adherence to WHO five moments is critical to ascertain the optimum reduction of HCAIs at UTHK. The participants' negative perception of cues to hand hygiene action and their perceived barriers to hand hygiene reveal the institutional (UTHK) gap concerning the implementation of WHO hand hygiene guidelines. Thus, the UTHK should put more effort on the effective implementation of the WHO hand hygiene guidelines.

\section{Acknowledgements}

The authors are thankful to Dr Pamela Meharry for the effort and support to help make this manuscript ready for publication. The principal investigator would like to recognise Dr Alexis Harerimana for his effort, support, encouragement and guidance that strengthen the principal investigator to be able to accomplish the task.

This article is published open access under the Creative Commons Attribution-NonCommercial NoDerivatives (CC BY-NC-ND 4.0). People can copy and redistribute the article only for noncommercial purposes and as long as they give appropriate credit to the authors. They cannot distribute any modified material obtained by remixing, transforming or building upon this article. See https:// creativecommons.org/licenses/by-nc-nd/4.0/

\section{References}

1. Kusain A, Olivo J. Assessing Healthcare Associated Infections and Hand Hygiene Perceptions amongst Healthcare Professionals. Int J Caring Sci. 2015;8:108-14.

2. Santos E, Celina L. Adherence to the five moments for hand hygiene among intensive care professionals. Rev Gaúcha Enferm. 2015;36.

3. Mbim EN, Mboto CI, Agbo BE. A Review of Nosocomial Infections in Sub-Saharan Africa. Br Microbiol Res J. 2016;15:1-11.

4. World Health Organization (Who). Guidelines on Core Components of Infection Prevention and Control Programmes at the National and Acute Health Care Facility Level [nternet]. 2016. Available from: https://www.who.int/infection-prevention/ publications/ipc-components-guidelines/en/

5. Lukas S, Hogan U, Muhirwa V, Davis C, Wong R. Establishment of a hospital-acquired infection surveillance system in a teaching hospital in Rwanda. Int J Infect Control. 2016;12:1-9.

6. Allegranzi B, Nejad SB, Combescure C, Graafmans W, Attar H, Donaldson L, et al. Burden of endemic health-care-associated infection in developing countries: Systematic review and meta-analysis. Lancet [Internet]. Elsevier Ltd; 2011;377:228-41. Available from: http://dx.doi.org/10.1016/S01406736(10)61458-4

7. WHO. Hand Hygiene Technical Reference Manual. 2009; Available from: http://apps.who.int/iris/ bitstream/10665/44196/1/9789241598606_eng. pdf

8. Abdella NM, Tefera MA, Eredie AE, Landers TF, Malefia YD, Alene and KA. Hand hygiene compliance and associated factors among health care providers in Gondar University. BMC Public Health. 2014;14.

9. Shinde MB, Mohite VR. A Study to Assess Knowledge, Attitude and Practices of Five Moments of Hand Hygiene among Nursing Staff and Students at a Tertiary Care Hospital at Karad. 2014;3:311-21.

10. Jeong SY, Kim KM. Influencing factors on hand hygiene behavior of nursing students based on theory of planned behavior: A descriptive survey study. Nurse Educ Today [Internet]. Elsevier Ltd; 2016;36:159-64. Available from: http://dx.doi. org/10.1016/j.nedt.2015.09.014 
11. Fox BC, Wavra T, Ash D, Mulligan D, Bennett YP, Nelson C, et al. use of a patient hand hygiene protocol to reduce hospital-acquired infections and improve nurses' handwashing. Am J Crit CARE. 2015;24:216-24.

12. Nteli C, Galanis P, Koumpagioti D, Poursanidis G, Panagiotopoulou E, Matziou V. Assessing the Effectiveness of an Educational Program on Compliance with Hand Hygiene in a Pediatric Intensive Care Unit. 2014;2014.

13. Taneja J, Mishra B. Promotion of Successful Hand Hygiene practices in the Intensive Care Units of a Tertiary Care Hospital. J Patient Saf Infect Control. Hospital Infection Society India; 2015;3:130-3.

14. Kumar, Dileep D. An epidemiological study on hand washing practices among health care workers in hospitals ofMangalore City. 2013;4:261-6.

15. Chacko LK. Knowledge of hand hygiene and its self reported practice among nursing students during clinical experience at a teaching hospital in Mangalore. J Patient Saf Infect Control [Internet]. Elsevier Ltd; 2014;2:55-7. Available from: http:// www.sciencedirect.com/science/article/pii/ S2214207X14000280

16. Ghanbari MK, Farazi AA, Shamsi M, Khorsandi M, Esharti B. Measurement of the health belief model $(\mathrm{HBM})$ in nurses hand hygiene among the hospitals. World Appl Sci J. 2014;31:811-8.

17. BUSAIDI. Healthcare workers and hand hygiene practice : A Literature Review. 2013;6:1-13.

18. Mearkle R, Houghton R, Bwonya D, Lindfield R. Barriers to hand hygiene in ophthalmic outpatients in Uganda : a mixed methods approach. J Ophthalmic Inflamm Infect [Internet]. Journal of Ophthalmic Inflammation and Infection; 2016; Available from: http:/ /dx.doi.org/10.1186/s12348-016-0077-0

19. Orji R, Vassileva J, Mandryk R. Towards an Effective
Health Interventions Design: An Extension of the Health Belief Model. Online J Public Health Inform. 2012;4.

20. Shojaei S, Farhadloo R, Aein A, Vahedian M. Effects of the Health Belief Model ( HBM)-Based Educational Program on the Nutritional Knowledge and Behaviors of CABG Patients. 2016;11:181-6.

21. Rwanda Ministry of Health. Rwanda Hospital Accreditation Standards. 2014;56.

22. Sax H, Allegranzi B. The World Health Organization hand hygiene observation method. Am J Infect Control. 2009;37:827-34.

23. Magnus TP, Marra AR, Camargo TZS, Victor E da S, Costa LSS da, Cardoso VJ, et al. Measuring hand hygiene compliance rates in different special care settings: A comparative study of methodologies. Int J Infect Dis. 2015;33:205-8.

24. Al-wazzan B, Salmeen Y, Ala A. Hand Hygiene Practices among Nursing Staff in Public Secondary Care Hospitals in Kuwait: Self-Report and Direct Observation. 2011;13110:326-31.

25. De Wandel D, Maes L, Labeau S, Vereecken C, Blot S. Behavioral determinants of hand hygiene compliance in intensive care units. Am J Crit Care. 2010;19:230-9.

26. Ryan C. Determinants of Hand Hygiene among Registered Nurses Caring for Critically Ill Infants in the Neonatal Intensive Care Unit. 2012; Available from: https:/ / scholar.uwindsor.ca/cgi/viewcontent. coi? article $=1220 \&$ context $=$ etd

27. United Nations International Children's Emergency Fund (UNICEF). Neonatal mortality. 2018. Available at: https://data.unicef.org/topic/childsurvival/neonatal-mortality/ 